\title{
PERANAN PENGURUS KELOMPOK TANI DALAM PROGRAM PENGEMBANGAN USAHA PANGAN MASYARAKAT DI KECAMATAN PALAS KABUPATEN LAMPUNG SELATAN PROVINSI LAMPUNG
}

\author{
(Roles of Farmer Group Administrators on Community Food Developmant Program \\ in Palas Subdistrict South Lampung Regency Lampung Province) \\ Maghfira Hariani, Sumaryo Gs, dan Begem Viantimala
}

\begin{abstract}
Jurusan Agribisnis, Fakultas Pertanian, Universitas Lampung, J1. Prof. Dr. Soemantri Brojonegoro No. 1 Bandar Lampung, 35145, e-mail: sumaryo.1964@fp.unila.ac.id
\end{abstract}

\begin{abstract}
This research aims to know the role level of farmer group administrators, and the factors related to the roles of farmer group administrators in community food developmant program (PUPM). Data of this research were collected from January to February 2019. This research uses a survey method and data are analyzed by descriptive and Rank Spearman analysis. The sample of the research is 2 Gapoktan from 2 villages which is taken puposively i.e Gapoktan Sejahtera (19 farmer groups) and Gapoktan Bersama (26 farmer groups). Then, from each farmer group is chosen 5 administrators consisting of leader, secretary, treasurer and 2 administrator members. Therefore, the number of samples is 69 administrators of farmer groups joining the program. The results of this research showed that the role lavel of farmer group administrators in the PUPM Program in Palas Subdistrict, South Lampung Regency is in the high classification. Factors related to the roles of farmer group administrators in the PUPM program are the education level and the motivation level of farmer group administrators.
\end{abstract}

Key words: administrator, farmer groups, PUPM

\section{PENDAHULUAN}

Sektor pertanian di Indonesia telah memberikan peran dalam perekonomian secara keseluruhan. Peran tersebut antara lain adalah sebagai penyedia bahan baku industri, penyedia bahan pangan masyarakat dan penyedia lapangan kerja (Safitri, Abidin dan Rosanti 2014). Pangan merupakan kebutuhan pokok bagi manusia. Oleh karena itu, untuk menjamin kelangsungan hidup manusia. maka ketersediaan akan pangan sangat perlu diperhatikan. Hal tersebut sangat didukung dengan latar belakang Negara Indonesia yang merupakan negara agraris dan memiliki banyak sekali sumber daya alam yang melimpah.

Pemenuhan pangan yang merupakan bagian dari hak asasi manusia dijamin dalam Undang-Undang Republik Indonesia Nomor 18 Tahun 2012 tentang pangan. Upaya pemerintah untuk menjaga komoditas pangan, salah satunya yaitu dengan melakukan kebijakan stabilitas harga pangan yang sesuai, agar produsen mendapatkan keuntungan dan konsumen dapat membeli bahan pangan dengan harga yang murah atau terjangkau. Harga komoditas pangan selalu berfluktuasi yang dapat merugikan para petani sebagai produsen, pengolah pangan, pedagang hingga konsumen yang berpotensi menimbulkan keresahan sosial. Oleh kerena itu, pemerintah Indonesia melalui Badan Ketahanan Pangan melakukan terobosan dalam mengatasi gejolak harga pangan yaitu melalui kegiatan Pengembangan Usaha Pangan Masyarakat (PUPM) (Peraturan Menteri Nomor 51 2018).

Program PUPM merupakan upaya pemerintah untuk menjaga stabilitas pasokan dan harga pangan dalam kegiatan memberdayakan Lembaga Usaha Pangan Masyarakat (LUPM) yaitu Gapoktan, Poktan, lembaga usaha masyarakat yang bergerak di bidang pangan dan Industri (Anggraini, Rangga dan Hasanuddin 2019). Kegiatan PUPM telah dilaksanakan sejak tahun 2016 beberapa provinsi di Indonesia, salah satunya Provinsi Lampung. Pada tahun 2018, kegiatan ini dikembangkan dengan beberapa penyempurnaan konsep dan teknis pelaksanaan sesuai dengan perkembangan dan permasalahan yang dihadapi selama melaksanakan kegiatan PUPM tahun 2016 dan 2017, baik di tingkat pusat maupun di daerah.

Kabupaten Lampung Selatan merupakan salah satu kabupaten yang melaksanakan program PUPM sejak tahun 2016. Menurut Badan Ketahanan Pangan Provinsi Lampung (2018), program PUPM sudah dikatakan berhasil pada tahun 2016, salah 
satunya di Kecamatan Palas. Keberhasilan program PUPM di Kecamatan Palas tidak terlepas dari peranan pengurus kelompok tani yang tersebar di delapan desa. Peranan pengurus kelompok tani menjadi bagian terpenting dari keberhasilan suatu program. Berdasarkan uraian tersebut, maka tujuan penelitian ini adalah untuk mengetahui tingkat peranan pengurus Poktan dalam program PUPM dan mengetahui faktor-faktor yang berhubungan dengan peranan pengurus Poktan dalam program PUPM.

\section{METODE PENELITIAN}

Penelitian ini dilakukan di Desa Badan Hurip dan Desa Bumidaya, Kecamatan Palas, Kabupaten Lampung Selatan. Penentuan lokasi desa dipilih secara sengaja (purposive) dengan pertimbangan bahwa kedua desa tersebut telah mengikuti kegiatan PUPM dari tahun 2016 sampai tahun 2018. Penelitian ini dilaksanakan pada bulan Januari sampai Februari 2019. Penentuan sampel hanya mengambil dua Gapoktan dari dua desa yaitu Gapoktan Sejahtera terdapat 19 Poktan dan Gapoktan Bersama terdapat 26 Poktan. Perwakilan kedua Gapoktan dipilih berdasarkan keaktifan masing-masing Gapoktan dan keikutsertaan Gapoktan sejak tahun 2016 dalam mengikuti kegiatan PUPM. Dari dua Gapoktan tersebut diperoleh jumlah populasi pengurus sebanyak 225 orang yang diambil secara sengaja (purposive) pada setiap Poktan sebanyak lima orang yang terdiri dari ketua, sekretaris, bendahara dan dua orang anggota pengurus, sehingga diperoleh jumlah pengurus sebanyak 69 orang yang ditetapkan berdasarkan pada rumus Yamane dalam Riduwan dan Kuncoro (2008):

$\mathrm{n}=\frac{\mathrm{N}}{\mathrm{Nd}^{2}+1}$

Keterangan :

$\mathrm{n} \quad=$ Jumlah sampel

$\mathrm{N}=$ Jumlah populasi

$\mathrm{d}=$ Presisi (ditetapkan $10 \%$ dengan tingkat kepercayaan 90\%)

Metode penelitian yang digunakan adalah metode survei. Data yang digunakan dalam penelitian ini adalah data primer dan data sekunder. Data primer meliputi data identitas responden dan variabel yang berhubungan dengan tingkat peranan pengurus Poktan dalam program PUPM. Data sekunder diperoleh dari studi pustaka/literatur, dan data-data yang didapat dari lembaga yang terkait pada penelitian ini yaitu Badan Ketahanan Pangan
Provinsi Lampung, Badan Ketahanan Pangan Kabupaten Lampung Selatan, serta instansi lain yang terkait.

Analisis data yang digunakan untuk menjawab tujuan pertama dalam penelitian ini adalah metode deskriptif. Analisis data yang digunakan untuk menjawab tujuan kedua dalam penelitian ini adalah metode analisis statistika non parametrik korelasi Rank Spearman dengan SPSS 22. Uji korelasi Rank Spearman digunakan untuk mencari hubugan antara variabel $\mathrm{X}$ (faktor-faktor yang diduga berhubungan dengan peranan pengurus, umur, tingkat pendidikan formal, luas lahan, tingkat pendapatan, tingkat motivasi, dan tingkat kekosmopolitan) dengan peranan pengurus Poktan dalam program PUPM. Rumus uji koefisien korelasi Rank Spearman (Siegel 1997) adalah:

$\mathrm{r}_{\mathrm{s}}=1-\frac{6 \sum_{\mathrm{i}-1}^{\mathrm{n}} \mathrm{di}^{2}}{\mathrm{n}^{3}}$.

Keterangan :

$r_{s} \quad=$ Penduga koefisien korelasi

di $\quad=$ Perbedaan setiap pasangan rank

$\mathrm{N} \quad=$ Jumlah responden

Kaidah pengambilan keputusan adalah :

1) Jika t-hitung $\geq$ t-tabel, maka terima $\mathrm{H}_{1}$, pada $(\alpha)=0,01$ atau 0,05 berarti terdapat hubungan antara kedua variabel yang diuji.

2) Jika t-hitung < t-tabel, maka tolak $\mathrm{H}_{1}$, pada $(\alpha)=0,01$ atau 0,05 berarti tidak terdapat hubungan antara kedua variabel yang diuji.

\section{HASIL DAN PEMBAHASAN}

\section{Identitas Responden}

Jumlah responden sebanyak 69 orang. Responden penelitian ini adalah pengurus Poktan yang mengikuti program PUPM di Kecamatan Palas Kabupaten Lampung Selatan. Sebagian besar umur responden berkisar antara 47-61 tahun dengan jumlah 34 orang $(49,28 \%)$. Sebagian besar tingkat pendidikan yang di tempuh oleh responden adalah pendidikan rendah (SD dan SMP) yaitu 45 orang $(65,22 \%)$. Pendidikan formal yang diikuti responden akan memudahkan dalam menerima dan menyerap pengetahuan tentang program PUPM maupun yang berkaitan dengan usahatani mereka. Pekerjaan utama responden yaitu sebagai petani padi, namun responden memiliki pekerjaan sampingan sebanyak 33 orang. Pekerjaan sampingan responden yaitu usahatani selain padi sawah sejumlah delapan orang $(11,59 \%)$, buruh 
tani sejumlah 11 orang $(15,94 \%)$, dan pekerjaan sampingan yang tidak berkaitan dengan pertanian sejumlah 14 orang $(20,28 \%)$ seperti pekerjaan sampingan wirausaha, pedagang, buruh bangunan, tukang, ojek, pegawai honorer dan PNS. Petani yang tidak memiliki pekerjaan sampingan terdapat 3 orang $(52,17 \%)$, hal ini karena responden berfokus pada budidaya tanaman padi sawah sebagai pekerjaan utama untuk memenuhi kebutuhan hidup.

\section{Tingkat Peranan Pengurus Poktan (Y)}

Menurut Soekanto (2002), peranan dapat dilihat apabila seseorang telah melaksanakan kewajiban dan hak sesuai status yang dimilikinya. Pengurus bertanggung jawab dalam segala sumber secara efisien untuk mencapai tujuan yang telah ditetapkan. Pengurus memiliki tugas dan fungsi dalam merancang dan mengimplementasikan strategi dalam suatu kegiatan lembaga yang baik (Aldila, Nikmatullah dan Hasanuddin 2018). Berdasarkan uraian tersebut, penelitian ini mengacu pada tugas dan fungsi Poktan dalam melaksanakan kegiatan sesuai dengan pedoman pelaksanaan dan teknis program PUPM antara lain: (1) menyebarluaskan dan mensosialisasikan kegiatan PUPM kepada anggota; (2) membimbing dan mengarahkan anggota dalam pelaksanaan kegiatan PUPM; (3) melakukan pembukuan penerimaan dana dan penggunaan dana kelompok, serta (4) melaporkan perkembangan pelaksanaan dan hasil kegiatan PUPM secara periodik. Berdasarkan Tabel 1 dapat dilihat bahwa rata-rata sebesar 51,30 tingkat peranan pengurus Poktan dalam program PUPM tergolong dalam klasifikasi tinggi.

\section{Menyebarluaskan dan Mensosialisasikan Kegiatan PUPM Kepada Anggota}

Pengurus Poktan dari ketua, sekretaris, bendahara dan anggota sudah intensif dalam melaksanakan sosialisasi dan penyebarlusan program ini. Sosialisasi diadakan tiga bulan sekali, mengenai pengadaan bahan baku, masalah harga, masalah mutu serta kebersihan pada produk yaitu beras. Pengurus mengadakan sosialisasi program tersebut dengan cara disampaikan secara langsung kepada para aggotanya yang dilakukan di rumah ketua ataupun anggota pada saat pertemuan dengan anggota dilaksanakan. Sebagian besar pengurus dan anggota Poktan sudah cukup memahami program PUPM. Hal ini memudahkan pengurus maupun anggota dalam menjalankan tugasnya dalam kegiatan PUPM ini.
Tabel 1. Rekapitulasi tingkat peranan pengurus Poktan dalam program PUPM

\begin{tabular}{cccc}
\hline \multirow{2}{*}{$\begin{array}{c}\text { Interval } \\
\text { (Skor) }\end{array}$} & Klasifikasi & \multicolumn{2}{c}{ Jumlah Responden } \\
\cline { 3 - 4 } & & $\begin{array}{c}\text { Pengurus } \\
\text { (jiwa) }\end{array}$ & $\begin{array}{c}\text { Persentase } \\
(\%)\end{array}$ \\
\hline $19,00-31,67$ & Rendah & 0 & 0,00 \\
$31,68-44,34$ & Sedang & 7 & 10,14 \\
$44,35-57,00$ & Tinggi & 62 & 88,85 \\
\hline Jumlah & & 69 & 100,00 \\
\hline Rata-rata : 51,30 (Tinggi) & & \\
\hline
\end{tabular}

\section{Membimbing dan Mengarahkan Anggota dalam Pelaksanaan Kegiatan PUPM}

Peranan pengurus Poktan dalam mengadakan bimbingan dan arahan kepada anggota sudah intensif yaitu tiap dua bulan sekali. Pengurus Poktan membimbing dan mengarahkan anggotanya melalui kegiatan seperti penyaluran dana dari pemerintah kepada Poktan, pelaporan perkembangan hasil kegiatan PUPM, menentukan target yang harus dicapai, dan menjaga kualitas produk yang dipasok. Fasilitas yang diberikan oleh pemerintah untuk kegiatan PUPM sudah cukup membantu pengurus dan anggotanya dalam menjalankan kegiatan tersebut. Adapun fasilitas yang diberikan berupa pengering dan alat penggilingan beras.

\section{Melakukan Pembukuan Penerimaan Dana dan Penggunaan Dana Kelompok}

Pembukuan sudah dilakukan secara rutin setiap satu bulan sekali. Pencatatan penerimaan dan penggunaan dana dilakukan oleh bendahara Poktan, namun dibantu juga oleh ketua dan sekretaris. Dana dari pemerintah untuk kegiatan PUPM ini sudah tersalurkan dengan baik. Pengurus Poktan juga sudah memperhatikan penggunaan dana yang digunakan untuk keperluan pada kegiatan PUPM.

\section{Melaporkan Perkembangan Pelaksanaan dan Hasil Kegiatan PUPM Secara Periodik}

Pelaporan perkembangan dan hasil pelaksanaan kegiatan PUPM sudah rutin, namun masih ada beberapa pengurus yang tidak selalu melaporkan perkembangan dan hasil kegiatannya. Pelaporan perkembangan pelaksanaan kegiatan yang dilakukan rutin setiap bulannya dengan cara disampaikan secara langsung, sedangkan untuk pelaporan hasil kegiatan dilakukan di akhir tahun. Laporan yang dilakukan pengurus Poktan mengenai total dan harga pembelian bahan pangan, 
stok gabah yang tersedia, jumlah penggunaan dana modal dan operasional serta sisa dana yang sudah digunakan. Pengurus mengirimkan laporan tersebut kepada Badan Ketahanan Pangan Kabupaten Lampung Selatan setiap setahun sekali.

\section{Faktor-faktor yang Berhubungan dengan Peranan Pengurus Poktan dalam Program PUPM (X)}

\section{Umur Pengurus (X1)}

Umur pengurus, dalam penelitian ini tergolong dalam klasifikasi produktif. Produktif atau tidaknya seseorang dalam bekerja dilihat dari umur seseorang tersebut (Ardiansyah, Sumaryo dan Yanfika 2014). Pada usia produktif, seseorang telah memiliki kemampuan, kesiapan dan keinginan dalam mengikuti Program PUPM. Semakin tua umur seseorang, maka kemungkinan besar akan semakin banyak juga pengalaman dan pengetahuan yang dimilikinya, sehingga semakin mudah orang tersebut untuk mengikuti program PUPM. Tabel 2 menunjukkan bahwa sebaran jumlah pengurus berdasarkan umur berkisar antara 47-61 tahun dengan jumlah pengurus sebanyak 34 orang $(49,28 \%)$.

\section{Tingkat Pendidikan Formal Pengurus (X2)}

Sebagian besar pendidikan formal pengurus Poktan di Kecamatan Palas tergolong dalam klasifikasi rendah. Rendahnya tingkat pendidikan formal menyebabkan sedikitnya pengetahuan dan keahlian yang dimiliki oleh pengurus, namun hal tersebut tidak menghalangi pengurus Poktan dalam menjalankan tugas karena pengurus Poktan yang terpilih memiliki hubungan sosial yang baik dengan masyarakat sekitarnya. Tabel 3 menunjukkan bahwa sebagian besar tingkat pendidikan formal pengurus yang dicapai oleh pengurus merupakan lulusan SD sampai dengan SMP yaitu sebanyak 45 orang $(65,22 \%)$.

\section{Luas Lahan Pengurus (X3)}

Luas lahan merupakan besarnya seluruh lahan yang dimiliki oleh pengurus dalam kegiatan PUPM. Tabel 4 menunjukkan bahwa sebagian besar luas lahan yang dimiliki pengurus Poktan di Kecamatan Palas tergolong dalam klasifikasi sempit yang berkisar antara $0,25-1,00$ ha yaitu sebanyak 43 orang $(62,32 \%)$. Luas lahan pengurus dengan klasifikasi sedang yaitu sebanyak 23 orang $(33,33 \%)$, sedangkan luas lahan pengurus dengan klasifikasi luas sebanyak 3 orang $(4,34 \%)$.
Tabel 2. Sebaran responden berdasarkan umur pengurus

\begin{tabular}{|c|c|c|c|}
\hline \multirow[b]{2}{*}{$\begin{array}{c}\text { Umur } \\
\text { (tahun) }\end{array}$} & \multirow[b]{2}{*}{ Klasifikasi } & \multicolumn{2}{|c|}{ Jumlah Responden } \\
\hline & & $\begin{array}{l}\text { Pengurus } \\
\text { (jiwa) }\end{array}$ & $\begin{array}{c}\text { Persentase } \\
(\%)\end{array}$ \\
\hline $31-46$ & Belum produktif & 31 & 44,93 \\
\hline $47-61$ & Produktif & 34 & 49,28 \\
\hline $62-76$ & Kurang produktif & 4 & 5,78 \\
\hline Jumlah & & 69 & 100,00 \\
\hline Rata-ra & ta : 47,46 (Produ & & \\
\hline
\end{tabular}

Tabel 3. Sebaran responden berdasarkan pendidikan formal pengurus

\begin{tabular}{llrr}
\hline \multirow{2}{*}{$\begin{array}{c}\text { Tingkat } \\
\text { Pendidikan }\end{array}$} & Klasifikasi & \multicolumn{2}{c}{ Jumlah Responden } \\
\cline { 3 - 4 } & & $\begin{array}{c}\text { Pengurus } \\
\text { (jiwa) }\end{array}$ & $\begin{array}{r}\text { Persentase } \\
\text { (\%) }\end{array}$ \\
\hline SD-SMP & Rendah & 45 & 65,22 \\
SMA/SMK & Sedang & 22 & 31,88 \\
D3/S1 & Tinggi & 2 & 2,90 \\
\hline Jumlah & & 69 & 100,00 \\
\hline Rata-rata : 9,12 (Rendah) & & \\
\hline
\end{tabular}

\section{Tingkat Pendapatan Pengurus (X4)}

Tingkat pendapatan pengurus merupakan besarnya pendapatan pengurus Poktan dari pendapatan utama dan pendapatan sampingan yang diperoleh. Tabel 5 menunjukkan bahwa musim tanam satu termasuk dalam klasifikasi rendah (62,32\%) dengan rata-rata sebesar Rp1.687.016. Sebagian besar pengurus Poktan tidak hanya berpenghasilan dari usahatani padi, namun juga dari luar usahatani padi maupun non usahatani (non farm). Tabel 6 menunjukkan bahwa pengurus Poktan memperoleh pendapatan selain dari usahatani padi yaitu usahatani jagung dan buruh tani dengan rata-rata pendapatan per tahun sebesar Rp2.707.970. Pendapatan pengurus dari luar usahatani (non farm) yaitu wirausaha, buruh bangunan, tukang, pedagang, pegawai honorer, PNS dan ojek dengan rata-rata pendapatan sebesar Rp4.207.243 per tahun.

Tabel 4. Sebaran responden berdasarkan luas lahan pengurus

\begin{tabular}{llrr}
\hline \multirow{2}{*}{$\begin{array}{c}\text { Luas Lahan } \\
\text { (ha) }\end{array}$} & Klasifikasi & \multicolumn{2}{c}{ Jumlah Responden } \\
\cline { 3 - 4 } & & $\begin{array}{c}\text { Pengurus } \\
\text { (jiwa) }\end{array}$ & \multicolumn{1}{c}{$\begin{array}{c}\text { Persentase } \\
(\%)\end{array}$} \\
\hline $0,25-1,00$ & Sempit & 43 & 62,32 \\
$1,01-1,75$ & Sedang & 23 & 33,33 \\
$1,76-2,50$ & Luas & 3 & 4,34 \\
\hline Jumlah & & 69 & 100,00 \\
\hline Rata-rata : 0,99 (Sempit) & \multicolumn{2}{c}{} \\
\hline
\end{tabular}


Tabel 5. Sebaran responden berdasarkan tingkat pendapatan pengurus per bulan

\begin{tabular}{clcc}
\hline Tingkat & & \multicolumn{2}{c}{ Jumlah Responden } \\
\cline { 3 - 4 } $\begin{array}{c}\text { Pendapatan } \\
\text { per bulan } \\
(\mathrm{Rp})\end{array}$ & Klasifikasi & $\begin{array}{c}\text { Pengurus } \\
\text { (jiwa) }\end{array}$ & $\begin{array}{c}\text { Persentase } \\
(\%)\end{array}$ \\
\hline $0-1.500 .000$ & Rendah & 43 & 62,32 \\
$1.501 .000-$ & Sedang & 19 & 27,54 \\
2.000 .000 & & & \\
$>2.001 .000$ & Tinggi & 7 & 10,14 \\
\hline Jumlah & & 69 & 100,00 \\
\hline Rata-rata $: 1.687 .016$ (Rendah) & & \\
\hline
\end{tabular}

Tabel 6. Sebaran responden berdasarkan tingkat pendapatan pengurus di luar usahatani padi dan non usahatani (non farm)

\begin{tabular}{lcc}
\hline Jenis Pekerjaan & $\begin{array}{c}\text { Jumlah } \\
\text { Pengurus } \\
\text { (jiwa) }\end{array}$ & $\begin{array}{c}\text { Rata-rata Tingkat } \\
\text { Pendapatan per tahun } \\
\text { (Rp) }\end{array}$ \\
\hline Usahatani jagung & 8 & 1.425 .362 \\
Buruh Tani & 11 & 1.282 .608 \\
Buruh Bangunan & 4 & 555.072 \\
Tukang & 2 & 272.463 \\
Wirausaha & 1 & 434.782 \\
Pedagang & 4 & 1.930 .434 \\
Pegawai Honorer & 1 & 260.869 \\
PNS & 1 & 521.739 \\
Ojek & 1 & 231.884 \\
\hline Jumlah & 33 & 6.915 .213 \\
\hline
\end{tabular}

\section{Tingkat Motivasi Pengurus (X5)}

Motivasi yang dimiliki pengurus Poktan berasal dari dalam diri mereka sendiri, ada pula dorongan dari luar lingkungan yang dapat membuat termotivasi untuk mengikuti program PUPM. Pengurus Poktan dengan tingkat motivasi yang tinggi mereka rela berkorban, tidak putus asa dan bersungguh-sungguh dalam menjalankan kegiatan PUPM, agar senantiasa puas dengan hasil yang dicapai. Pengurus Poktan dengan tingkat motivasi rendah cenderung bersifat mudah putus asa, kurang berkorban dan bersungguh-sungguh dalam menjalankan kegiatan PUPM tersebut.

Tabel 7. Sebaran responden berdasarkan tingkat motivasi pengurus

\begin{tabular}{llrr}
\hline \multirow{2}{*}{$\begin{array}{c}\text { Interval } \\
\text { (Skor) }\end{array}$} & \multirow{2}{*}{ Klasifikasi } & \multicolumn{2}{c}{ Jumlah Responden } \\
\cline { 3 - 4 } & & $\begin{array}{c}\text { Pengurus } \\
\text { (jiwa) }\end{array}$ & $\begin{array}{c}\text { Persentase } \\
(\%)\end{array}$ \\
\hline 12,00-20,00 & Rendah & 0 & 0,00 \\
$20,01-28,00$ & Sedang & 16 & 23,18 \\
$28,01-36,00$ & Tinggi & 53 & 76,81 \\
\hline Jumlah & 69 & 100,00 \\
\hline Rata-rata : 31,45 ( Sedang) & & \\
\hline
\end{tabular}

Tabel 8. Sebaran responden berdasarkan tingkat kekosmopolitan pengurus

\begin{tabular}{lcrr}
\hline \multirow{2}{*}{$\begin{array}{c}\text { Interval } \\
\text { (Skor) }\end{array}$} & Klasifikasi & \multicolumn{2}{c}{ Jumlah Responden } \\
\cline { 3 - 4 } & $\begin{array}{c}\text { Pengurus } \\
\text { (jiwa) }\end{array}$ & $\begin{array}{r}\text { Persentase } \\
(\%)\end{array}$ \\
\hline $6,00-1,00$ & Kurang Kosmopolit & 7 & 10,14 \\
10,01-14,00 Cukup Kosmopolit & 47 & 68,12 \\
14,01-18,00 Kosmopolit & 15 & 21,74 \\
\hline \multicolumn{2}{l}{ Jumlah } & 69 & 100,00 \\
\hline \multicolumn{2}{l}{ Rata-rata : 12,35 (Cukup Kosmopolit) } \\
\hline
\end{tabular}

Tabel 7 menunjukkan bahwa tingkat motivasi pengurus berada diklasifikasi tinggi sebanyak 53 orang $(76,81 \%)$. Hal ini menunjukkan bahwa tingkat motivasi pengurus dalam melaksanakan program PUPM sudah cukup baik.

\section{Tingkat Kekosmopolitan Pengurus (X6)}

Sebagian besar pengurus Poktan sudah aktif dalam berinteraksi dengan tetangga, tokoh masyarakat setempat maupun anggota Poktan lainnya. Pengurus Poktan juga sering dan aktif mengadakan pertemuan dan anjangsana dengan tokoh-tokoh masyarakat dari desa lain. Sebagian pengurus Poktan sudah memanfaatkan media massa, namun ada beberapa pengurus belum memanfaatkan media massa seperti radio dan internet. Media massa internet belum sepenuhnya dimanfaatkan oleh pengurus Poktan sebagai alat untuk mencari informasi yang berkaitan dengan program PUPM maupun pertanian masa kini. Media sosial sudah dimanfaatkan oleh pengurus sebagai sarana berinteraksi melalui whatsapp dan facebook. Tabel 8 menunjukkan bahwa tingkat kekosmopolitan pengurus berada dalam klasifikasi cukup kosmopolit sebanyak 47 orang $(68,12 \%)$.

\section{Hasil Pengujian Hipotesis}

Hubungan antara variabel X (faktor-faktor yang berhubungan dengan peranan pengurus Poktan) dengan variabel $\mathrm{Y}$ (tingkat peranan pengurus Poktan dalam program PUPM) dalam penelitian ini menggunakan statistik non parametrik uji korelasi Rank Spearman. Hasil pengujian statistik antara variabel X dan Y dapat dilihat pada Tabel 9.

\section{Hubungan antara Umur Pengurus dengan Peranan Pengurus Poktan dalam Program PUPM}

Hasil pengujian hipotesis hubungan antara umur pengurus dengan peranan pengurus Poktan diperoleh hasil t-hitung sebesar 0,221. 
Tabel 9. Hasil pengujian statistik faktor-faktor yang berhubungan dengan peranan pengurus Poktan dalam program PUPM

\begin{tabular}{|c|c|c|c|c|c|}
\hline \multirow{2}{*}{ Variabel X } & \multirow{2}{*}{$\begin{array}{c}\text { Variabel } \\
\text { Y }\end{array}$} & \multirow[b]{2}{*}{$\mathrm{r}_{\mathrm{s}}$} & \multirow{2}{*}{ t-hitung } & \multicolumn{2}{|c|}{ t-tabel } \\
\hline & & & & $\alpha 0,05$ & $\alpha 0,01$ \\
\hline Umur pengurus & & 0,027 & $0,221^{\text {tn }}$ & 1,667 & 2,382 \\
\hline $\begin{array}{l}\text { Tingkat pendidikan } \\
\text { pengurus }\end{array}$ & & 0,297 & $2,546 * *$ & 1,667 & 2,382 \\
\hline $\begin{array}{l}\text { Luas lahan } \\
\text { pengurus }\end{array}$ & Peranan & $-0,036$ & $-0,294^{\mathrm{tn}}$ & 1,667 & 2,382 \\
\hline $\begin{array}{l}\text { Tingkat } \\
\text { pendapatan } \\
\text { pengurus }\end{array}$ & $\begin{array}{l}\text { Pengurus } \\
\text { Poktan } \\
\text { dalam }\end{array}$ & $-0,128$ & $-0,224^{\text {tn }}$ & 1,667 & 2,382 \\
\hline $\begin{array}{l}\text { Tingkat motivasi } \\
\text { pengurus dalam } \\
\text { program PUPM }\end{array}$ & $\begin{array}{l}\text { Program } \\
\text { PUPM }\end{array}$ & 0,377 & $3,278 * *$ & 1,667 & 2,382 \\
\hline $\begin{array}{l}\text { Tingkat } \\
\text { kekosmopolitan } \\
\text { pengurus }\end{array}$ & & 0,151 & $1,250^{\operatorname{tn}}$ & 1,667 & 2,382 \\
\hline \multicolumn{6}{|l|}{ Keterangan: } \\
\hline $\begin{array}{ll}\mathrm{r}_{\mathrm{s}} & =\text { Penduga koefis } \\
* & =\text { Nyata pada tara } \\
* * & =\text { Sangat nyata pa }\end{array}$ & $\begin{array}{l}\text { sien korelasi } \\
\text { af kepercaya } \\
\text { ada taraf kep }\end{array}$ & $\begin{array}{l}\text { an } 95 \% \\
\text { ercaya }\end{array}$ & $\begin{array}{l}(\mathrm{t}-\mathrm{tabel}=1 \\
\mathrm{n} 99 \%(\mathrm{t}-\mathrm{tal}\end{array}$ & $\begin{array}{l}667) \\
\mathrm{bel}=2,38\end{array}$ & \\
\hline
\end{tabular}

Hal ini menjelaskan bahwa nilai t-hitung lebih kecil dibandingkan dengan nilai t-tabel sebesar $1,667(95,00 \%)$ atau $2,382(99,99 \%)$ yang berarti tolak $\mathrm{H}_{1}$, yaitu tidak terdapat hubungan yang nyata antara umur pengurus dengan peranan pengurus Poktan dalam program PUPM di Kecamatan Palas Kabupaten Lampung Selatan.

Responden yang berumur produktif cenderung lebih aktif dalam menjalankan tugas dan fungsinya sebagai pengurus dalam menerima sesuatu hal yang baru. Dilihat dari peranan pengurus pada penelitian ini umur pengurus termasuk dalam klasifikasi produktif. Hal ini menjelaskan bahwa tidak adanya hubungan antara umur pengurus dengan peranan pengurus Poktan, yaitu disebabkan oleh umur pengurus berkelompok pada klasifikasi produktif $(95,65 \%)$, sehingga data tidak menyebar secara normal, maka berapapun umur pengurus produktif atau kurang produktif tidak ada hubungan dengan peranan pengurus Poktan dalam program PUPM.

\section{Hubungan antara Tingkat Pendidikan Pengurus dengan Peranan Pengurus Poktan dalam Program PUPM}

Hasil pengujian hipotesis hubungan antara tingkat pendidikan dengan peranan pengurus Poktan diperoleh hasil t-hitung sebesar 2,546. Hal ini menjelaskan bahwa nilai t-hitung lebih besar dibandingkan dengan nilai t-tabel sebesar 1,667 $(95,00 \%)$ atau 2,382 (99,99\%), maka terima H1 dan tolak H0 yang berarti terdapat hubungan yang nyata antara tingkat pendidikan pengurus dengan peranan pengurus Poktan dalam program PUPM di Kecamatan Palas Kabupaten Lampung Selatan. Pengurus Poktan yang berpendidikan rendah menyebabkan sedikitnya pengetahuan dan keahlian yang dimilikinya. Namun hal tersebut tidak menghalangi pengurus Poktan dalam menjalankan tugasnya. Pengurus Poktan memiliki hubungan sosial yang baik dengan masyarakat sekitar desa maupun luar desa. Sebagian besar pengurus juga sudah memiliki pengalaman yang cukup dalam bidang pertanian, sehingga dapat membantu pengurus menjalankan tugasnya dalam kegiatan PUPM. Hasil penelitian ini sesuai dengan penelitian Wiyono (2010) yang berjudul peranan pengurus dalam keberhasilan pos pelayanan pertanian (posyanluhtan) menyatakan bahwa terdapat hubungan yang nyata antara tingkat pendidikan formal dengan peranan pengurus dalam keberhasilan posyanluhtan.

\section{Hubungan antara Luas Lahan Pengurus dengan Peranan Pengurus Poktan dalam Program PUPM}

Hasil pengujian hipotesis hubungan antara luas lahan pengurus dengan peranan pengurus Poktan diperoleh hasil t-hitung sebesar -0,294. Hal ini berarti bahwa nilai t-hitung lebih kecil dibandingkan dengan nilai t-tabel sebesar 1,667 $(95,00 \%)$ atau $2,382(99,99 \%)$ yang artinya tolak $\mathrm{H} 1$, yaitu tidak terdapat hubungan yang nyata antara luas lahan pengurus dengan peranan pengurus Poktan dalam program PUPM di Kecamatan Palas Kabupaten Lampung Selatan. Berdasarkan hasil pengujian statistik lapangan bahwa luas lahan yang dimiliki pengurus tidak berhubungan dengan peranan pengurus Poktan dalam kegiatan PUPM. Hal ini dapat dijelaskan bahwa tidak ada hubungan antara luas lahan pengurus dengan peranan pengurus Poktan, disebabkan karena luas lahan pengurus berkelompok pada klasifikasi sempit (62,32\%), sehingga data tidak menyebar secara normal, maka peranan pengurus dalam program PUPM tidak ada hubungan dengan besar atau kecilnya luas lahan yang dimiliki oleh pengurus dalam kegiatan PUPM.

\section{Hubungan antara Tingkat Pendapatan Pengurus dengan Peranan Pengurus Poktan dalam Program PUPM}

Hasil pengujian hipotesis hubungan antara tingkat pendapatan pengurus dengan peranan pengurus Poktan diperoleh hasil t-hitung sebesar -0,224. Hal 
ini menjelaskan bahwa nilai t-hitung lebih kecil dibandingkan dengan nilai t-tabel sebesar 1,667 $(95,00 \%)$ atau 2,382 $(99,99 \%)$, maka tolak $\mathrm{H} 1$ yang artinya tidak terdapat hubungan yang nyata antara tingkat pendapatan pengurus dengan peranan pengurus Poktan dalam program PUPM di Kecamatan Palas Kabupaten Lampung Selatan. Kondisi ini membuktikan bahwa tinggi maupun rendahnya pendapatan pengurus tidak berhubungan dengan peranan pengurus Poktan dalam program PUPM. Meskipun pengurus mengetahui hak dan kewajibannya, namun mereka memiliki pekerjan lain untuk memenuhi kebutuhan sekunder dan tersier mereka, berarti pekerjaan sebagai pengurus bukanlah pekerjaan utama mereka. Hal ini dapat dijelaskan bahwa tidak ada hubungan antara pendapatan pengurus dengan peranan pengurus Poktan. Pendapatan pengurus berkelompok pada klasifikasi rendah $(62,32 \%)$, sehingga data tidak menyebar secara normal, maka pengurus yang memiliki pendapatan tinggi maupun rendah tidak berhubungan dengan peranan pengurus Poktan dalam program PUPM.

\section{Hubungan antara Tingkat Motivasi Pengurus dengan Peranan Pengurus Poktan dalam Program PUPM}

Hasil pengujian hipotesis hubungan antara tingkat motivasi pengurus dengan peranan pengurus Poktan diperoleh hasil thitung sebesar 3,278. Hal ini menunjukkan bahwa nilai t-hitung lebih besar dibandingkan dengan nilai t-tabel sebesar 1,667 $(95,00 \%)$ atau 2,382 $(99,99 \%)$, maka terima $\mathrm{H} 1$ dan tolak HO yang berarti terdapat hubungan yang nyata antara tingkat motivasi pengurus dengan peranan pengurus Poktan dalam program PUPM di Kecamatan Palas Kabupaten Lampung Selatan.

Berdasarkan hasil di lapangan, sebagian besar motivasi pengurus berasal dari dalam diri mereka sendiri, namun ada pula dorongan dari luar lingkungan dan orang-orang sekitarnya seperti teman, keluarga, anggota kelompok tani, maupun jajaran pengurus lainnya yang membuat termotivasi untuk mengikuti Program PUPM. Pengurus Poktan sudah bersungguh-sungguh dan berkorban waktu, tenaga, dan uang untuk menjalankan tugas dan fungsinya dalam kegiatan PUPM. Hasil penelitian ini sesuai dengan penelitian Purnomo (2014) yang berjudul peranan karang taruna berstatus mahasiswa dalam meningkatkan kinerja organisasi yang menyatakan bahwa pemberian motivasi merupakan salah satu faktor pendukung untuk menjalankan kerjasama dalam suatu organisasi karang taruna.
Hubungan antara Tingkat Kekosmopolitan Pengurus dengan Peranan Pengurus Poktan dalam Program PUPM

Hasil pengujian hipotesis hubungan antara tingkat kekosmopolitan pengurus dengan peranan pengurus Poktan diperoleh hasil t-hitung sebesar 1,250. Hal ini menunjukkan bahwa nilai t-hitung lebih kecil dibandingkan dengan nilai t-tabel sebesar 1,667 $(95,00 \%)$ atau 2,382 $(99,99 \%)$ yang berarti tolak $\mathrm{H} 1$, yaitu tidak terdapat hubungan yang nyata antara tingkat kekosmopolitan pengurus dengan peranan pengrus Poktan dalam program PUPM di Kecamatan Palas Kabupaten Lampung Selatan. Hal ini dapat dijelaskan bahwa tidak ada hubungan antara tingkat kosmopolit pengurus dengan peranan pengurus Poktan, disebabkan karena tingkat kosmopolit pengurus berkelompok pada klasifikasi cukup kosmopolit $(68,12 \%)$, sehingga data tidak menyebar secara normal, maka pengurus Poktan yang kosmopolit maupun kurang kosmopolit tidak ada hubungan dengan peranan pengurus dalam program PUPM. Berdasarkan pengamatan di lapangan bahwa pengurus Poktan kurang aktif dalam melakukan perjalanan ke luar kota guna mendapatkan informasi seputar pertanian maupun luar pertanian di kota-kota lain. Pengurus Poktan juga kurang memanfaatkan media massa untuk berinteraksi dan memperoleh informasi yang menunjang proses kegiatan PUPM maupun di luar kegiatan.

\section{KESIMPULAN}

Berdasarkan hasil penelitian ini dapat diambil kesimpulan, tingkat peranan pengurus Poktan dalam Program PUPM di Kecamatan Palas Kabupaten Lampung Selatan termasuk dalam klasifikasi tinggi, artinya pengurus telah melakukan peranannya dengan sangat baik yaitu dengan cara menyebarluaskan dan mensosialisasikan program kepada anggota, membimbing dan mengarahkan anggota, melakukan pembukuan penerimaan dan penggunaan dan serta melaporkan perkembangan pelaksanaan dan hasil kegiatan PUPM secara periodik. Terdapat hubungan yang nyata antara tingkat pendidikan dan tingkat motivasi pengurus dengan peranan pengurus Poktan dalam program PUPM. Tidak terdapat hubungan yang nyata antara umur pengurus, luas lahan pengurus,tingkat pendapatan pengurus, dan tingkat kekosmopolitan dengan peranan pengurus Poktan dalam program PUPM. 


\section{DAFTAR PUSTAKA}

Aldila B, D Nikmatullah, dan $\mathrm{T}$ Hasanuddin. 2018. Faktor-faktor yang berhubungan dengan peranan pengurus Badan Usaha Milik Pekon Pekon Gisting Bawah Kecamatan Gisting Kabupaten Tanggamus. JIIA, 6 (2) : 214-221. http://jurnal.fp.unila. ac.id/index.php/JIA/article/view/2788/2334 [20 September 2019].

Anggraini R, KK Rangga, dan T Hasanuddin. 2019. Partisipasi petani dan keberhasilan Program Pengembangan Usaha Pangan Masyarakat (PUPM) di Kecamatan Palas Kabupaten Lampung Selatan. JIIA, 7 (1): 113-119. http://jurnal.fp.unila.ac.id/index. php/JIA/article/view/3339/2560 [13 Juli 2019].

Ardiansyah A, Sumaryo, dan H Yanfika. 2014. Persepsi petani terhadap kinerja penyuluh di BP3K sebagai Model Center Of Excellence (COE) Kecamatan Metro Barat Kota Metro. JIIA, 2 (2): 182-189. http://jurnal.fp.unila. ac.id/index.php/JIA/article/view/743/684 [5 November 2019].

Badan Ketahanan Pangan Provinsi Lampung. 2018. Pengembangan Usaha Pangan Masyarakat. Badan Ketahanan Pangan. Provinsi Lampung. Bandar Lampung.
Peraturan Menteri Pertanian Nomor 51. 2018. Pedoman Teknis Pengembangan Usaha Pangan Masyarakat 2018. http://bkp. pertanian.go.id [10 Februari 2018].

Purnomo DA. 2014. Peranan karang taruna berstatus mahasiswa dalam meningkatkan kinerja organisasi. Journal Student UNY : 114. http://journal.student.uny.ac.id/ojs/index. php/pls/article/viewFile/1806/1584 [8 September 2019].

Riduwan dan Kuncoro EA. 2008. Cara Menggunakan dan Memakai Analisis Jalur (Path Analysis). Alfabeta. Bandung.

Safitri Y, Z Abidin, dan N Rosanti. 2014. Kinerja dan nilai tambah agroindustri sabut kelapa pada Kawasan Usaha Agroindustri Terpadu (KUAT) di Kecamatan Pesisir Selatan Kabupaten Pesisir Barat. JIIA, 2 (2): 166173.http://jurnal.fp.unila.ac.id/index.php/JIA /article/view/740/681 [3 Desember 2019].

Siegel S. 1997. Statistik Non-Parametrik. PT Gramedia Pustaka Utama. Jakarta.

Soekanto S. 2002. Teori Peranan. Bumi Askara. Jakarta.

Wiyono. 2010. Peranan Pengurus dalam Keberhasilan Pos Pelayanan Penyuluhan Pertanian (Posyanluhtan) di Desa Pardasuka Kecamatan Katibung Kabupaten Lampung Selatan. Skripsi. Fakultas Pertanian. Universitas Lampung. Bandar Lampung. 